\title{
Development of Mathematics Teacher's Preparation Programs in the Light of STEM Education
}

\author{
Seham Abdulrahman Sulayman Aloraini \\ Correspondence: Seham Abdulrahman Sulayman Aloraini, Imam University, Saudi Arabia.
}

Received: October 11, 2019

doi:10.11114/jets.v8i4.4707
Accepted: December 9, 2019 Online Published: February 7, 2020

URL: https://doi.org/10.11114/jets.v8i4.4707

\begin{abstract}
The study aimed to reveal the reality of keeping pace with the preparation programs of mathematics teachers to the requirements of STEM education and develop a suggested scenario for the development of mathematics teacher preparation programs in the light of the requirements of STEM. To this end, the analytical descriptive method was conducted, and the researcher built a list of requirements in the light of STEM education which should be included in the programs of preparation of mathematics teachers. The questionnaire was used as a data collection tool. The study sample consisted of (47) faculty members in the preparation programs of mathematics teachers in Saudi universities.

The main findings were as follows: (1) to build a list of STEM education requirements that should be included in the math teacher preparation programs, (2) the availability of professional competence of pre-service mathematics teachers in the light of the STEM was weak $(\mathrm{M}=1.49,50 \%)$, (3) the commitment of mathematics students-teachers to improve the performance of learners with a medium means of 2.19 , and $73 \%$, (4) the use of mathematics students-teachers established the foundations of highly systematic thinking, is high, with means an average of 2.37 and $79 \%$, and (5) the interaction of mathematics students-teachers in the educational community is high, with means of 2.46 , and $82 \%$. On the basis of these results, a proposed development of programs for the preparation of mathematics teachers in Saudi universities was developed.
\end{abstract}

Keywords: mathematics students, teachers preparation, STEM education

\section{Introduction}

The modern age is known for rapid development particularly in science and technology. This led to dramatic changes in several spheres of life. The most prominent change is the use of advanced modern technology in all modern knowledge aspects. To keep abreast with the technology, it is necessary to develop education as it is the key for nations development.

One of the recent trends recommended by development plans of the Ministry of Education in Saudi Arabia is to adopt Science Technology Engineering Mathematics (STEM). It is believed to be one of the most global trends that proved to be effective over the last three decades. Mathematics is a scientific technological subject that needs special capabilities as it is based on abstractness and accuracy. Therefore, it requires a competent instructor who possesses both knowledge and pedagogy that enable him/her to practice teaching in an efficient and effective way (Yousuf, 2009). Michel (2004) points out that the role of teachers is crucial as he "forms basic instructional practices in Math and he is the only one who generalizes the appropriate experience to students to push them to Math not far away from it" "p.22".

Elipane (2012) argues that to augment teacher's efficiency, it is mandate for teachers to apply some criteria such as mastery and knowledge of the contents, mastery of instructional practices and interpersonal communication skills to overcome multicultural students, matching the needs of students and capabilities, and integrating the syllabus, pedagogy, and evaluation with learning and instruction content.

Given the pivotal role of Math teacher in teaching process and his professional development, it is of paramount need to develop pre-teacher training in light of STEM. The complementary relationship among Science, technology, Engineering, and Math becomes a contemporary requirement to develop teaching Math and to assist teachers to acquire appropriate mental skills and follow scientific ways in thinking, research, investigation, and improve their innovative capabilities. Hence, this study aims to provide a suggested development to pre-service teachers programs of Math in light of STEM. 


\section{Statement of the problem}

Despite the fact that teaching Science and Math in secondary schools is still not up to the desired goal to satisfy students' intellectual capacities, answer their questions about the natural world, and provide them with functional and effective scientific experiences, many serious attempts were done to bring science and mathematics closer to real practical education objectives, which casts a shadow on the role of the teacher, requiring care to the develop teacher's professionalism and the skills that enable him able to achieve this role. In this regard, Kingdom of Saudi Arabia is paying much care to develop teachers as reflected from the trends of the ninth development plan (2010-2014) which entail the commitments to improve the efficiency of the human capabilities in education and pedagogy to be able to adapt modern curricula (Ministry of Economy and Planning, 2010, p. 40). A number of conferences were held that emphasized the importance of developing the teacher. For example, the international conference entitled "Teacher of the Future: Preparation and Development", organized by the College of Education, King Saud University, Riyadh, 7-10-2015, and the fifth conference for teachers' preparation entitled "preparing and training the teacher in light of the demands of developments of the modern era, "organized by the Faculty of Education, Umm Al-Qura University during the period from 3-4 / 2/2016.

Many research findings demonstrated the obstacles that encountered by faculties of education in regards to admission policy, pre-service teachers preparation courses, methods of teaching, evaluation, and pre-service teachers programs (Kalogiannakis, \& Papadakis, 2019; 2018; Papadakis, 2018).

This requires the institutions of teacher preparation in the Arab world to adopt a holistic approach to reform the institutions that prepare teachers and develop their programs and curricula on the basis of and clear and comprehensive standards. The whole world is involved in a single global market in which all countries compete to achieve high quality and this requires that education must succeed in maximizing the human capacity involved in the development process and advance the capacity of the teacher who is responsible for building the generations (Alsaloos \& Almaiman, 2010, p.41). The development of teacher training programs has no longer relied on immediate spontaneous responses and the swing mood of their constituents, the mutual interests of teaching staff, the influence of pressure groups within or outside teacher training colleges and their role in micro-development or informal modification and the continuity of patterns in preparation that do not achieve graduates of these colleges what it intend to achieve from "professionalism" in performance; it has become a cooperative scientific process based on perseverance, performance and demonstration according to specific criteria (Al-Nabawi, 2007, p. 32).

Some studies and conferences have recommended the need to advance, improve and develop the teaching practices of the Math teacher in the light of the integration of technology, engineering and mathematics (STEM). The study of Muhaysen and Khaja, 2015; Ganem, 2015) have recommended improvement of performance skills of teachers in light of integrity. Besides, the study of Sivan and Mohammed (2010) emphasized the role of the interaction among Math, Technology and Engineering in the development of teachers' instructional performance skills through their teaching of subjects that integrate (STEM).

However, many studies have pointed to the weakness of adopting modern trends in the teacher's preparation, including the integration of (STEM). The studies of (Siham Murad, 2014; Ahlam Al-Shuhaimia, 2015; Khadja, 2016) have stressed training needs for teachers in the context of STEM integration, as evidenced by the effectiveness of this approach in improving the performance of teachers (Sivan \& Muhammad, 2010; Alshahrani, 2013, Nelson, 2015) for the effectiveness of this trend in improving teachers' performance.

Based on the above, and due to the lack of a great deal in the curriculum of the current secondary stage to include the main skills in science and mathematics in an effective functional manner that helps to provide students with a scientific knowledge base, skills and practical experience suitable to understand the natural world. Moreover, the lack to cope with life problems, building and designing current curricula in entailing integrated mathematics approaches focused on research, investigation, problem solving, embedding scientific and logical thinking skills, development of self-assessment abilities, decision-making, and development of students' skills in irrigation skills Engineering, scientific skills, and technology application capabilities in life situations. Thus, there is an urgent need to develop programs for preparing of Math teachers in the light of the advent of STEM integration in their teaching practices.

\section{Research questions:}

The study attempts to answer the following questions;

1). What are the requirement of STEM that should be included in professional program for Math teachers' preparation?

2). What is the reality of the preparation programs of Math teachers in the light of STEM orientation? 
3). What is the proposed development of the professional program for the preparation of Math teachers in the light of the STEM orientation?

\section{Study Objectives}

The study aims to achieve the following objectives;

1) prepare a list of STEM standards that should be included in the professional program for the preparation of mathematics teachers, 2) reveal the reality of keeping pace with the preparation programs of mathematics teachers to the requirements of STEM, and 3) provide a suggested scenario for the development of mathematics teacher preparation programs in light of STEM requirements.

\section{Significance of the Study}

The study will be of importance to the field of knowledge as for the following reasons:

1) The study provides objective tools as a list of STEM standards that can be used by educational professionals to evaluate the level of mathematics teacher preparation programs.

2) The researcher hopes that the proposed development of mathematics teacher programs in the light of STEM's approach will help mathematics teachers to boost strengths and address weaknesses in their teaching practices.

\section{Definition of Terms}

\section{Math teachers preparatory program}

Zaitoun (2006) defines the elementary teacher preparatory program as: "programs organized by the colleges of education to be attended by students after completion of secondary school that aims to prepare them academically, educationally and culturally for the practice of teaching, in the primary stage. The duration of the study is four years, after which the student is granted a bachelor's degree in elementary education (p. 68).

The researcher defines it as a set of facts, standards, values, experiences and activities that are included in the specialized and educational courses in the colleges of preparing mathematics teachers and the preceded plans aimed at achieving academic accreditation standards.

\section{STEM}

Tsupros, Kohler, and Hallinen (2009) defined it as: "A multidisciplinary approach in which scientific concepts are associated with natural phenomena, and learners can apply science, technology, engineering and Math in contexts that make communication between school and society effective, enabling the acquisition of scientific culture and the ability to compete in the global economy "(p. 18).

The researcher defines it as a global trend, consisting of four areas: Science, Technology, Engineering, and Mathematics, which are studied in an integrated rather than isolated manner, thus contributing to the coherence of knowledge acquired with their applications.

\section{Theoretical Background and Previous Studies}

The philosophy of integration STEM in learning mathematics began to be integrated as a subject and then developed into the integration of mathematics, science and technology through MST, which focuses on the interactive relationships among mathematics, science and technology by organizing the study content on teaching attitudes that remove barriers between mathematics, science and technology when taught (Sevin and Muhammad, 2010, p. 300). The recent developments in integration of teaching and learning Math are their integration with science, technology and engineering materials in the so-called STEM integration.

\section{STEM}

The integration of science, technology, engineering and mathematics (STEM) is vital for the future, in which the disciplines of natural sciences and mathematics are integrated as basic sciences of life, technology and engineering as applications of such sciences in an equal way to achieve the idea of integrative education. Several definitions of the concept of (STEM) were proposed by Tsupros, Kohler and Hallinen (2009) as cited above in the defnition of terms.

STEM stands for the first letters of Science, Technology, Engineering and Mathematics. It means the integration of subjects in these areas and disciplines within and outside the school. The STEM approach is in the integrated curriculum, as

Science: studying the natural world around us, and the nature of science. It includes knowledge, skills, scientific and creative thinking methods and decision-making.

Technology: applied scientific, engineering and computer sciences. 
Engineering: Engineering design and ability to build models and designs.

Mathematics: The basics of mathematics needed to solve mathematical problems (Ghanem, 2011, p. 23).

Objectives of STEM

STEM's goal is to develop learning science, technology, engineering and mathematics education, thereby contributing to the production of innovative minds. In a document issued by the National Research Council (NRC, 2011, pp. 4-5), three long-term goals, issued by the United States of America, are widely adopted for teaching STEM in general education (K-12). Besides, the objectives focus on learning the content and practices of STEM, developing positive attitudes towards STEM areas, and preparing students to be lifelong learners. These objectives are:

1: Increase in the number of learners seeking advanced degrees and positions in STEM fields.

2: Increase the qualified workforce according to the STEM approach.

3: Increase the knowledge of all STEM learners, including those who do not want to pursue additional STEM positions or further study additional information about STEM.

Importance of Studying STEM

This trend is one of the most important scientific trends in curricula design, and proved effective for decades in the United States, the United Kingdom and South Africa. It is integrated into the construction of the spirit of science and mathematics with technology, relies on education through the application of practical activities, digital technology, activities based on experience through discovery and investigation, handcraft activities, scientific and logical thinking activities, and decision-making. This trend is based on integrated a conceptual experience, it focuses on problem solving and investigation, intensive application of activities and centers on specific and self-directed experiences, empirical and practical research in binaries, realistic multidimensional and performance-based assessment teams, and creative critic thinking (Ghanem, 2011, p. 109).

Instructional Practices in light of STEM

In this modern age there is a new vision of the nature of science. Science is not a set of facts, knowledge and laws that the learner must know. It requires the application of that knowledge in practical situations that may encounter in everyday life. The National Research Council (NRC, 2001, p.11) provided some recommendations for the development of educational materials in school mathematics, including:

- Educational materials should be integrated with activities and strategies, supporting teachers to help all learners become proficient in mathematics.

- Learning inquiry-based: Learners have to research and investigate major problems and challenges and deepen understanding of environmental phenomena and issues. The teacher uses brainstorming to generate solutions to problems.

- Learning Project-based through which learners develop creative and practical projects when involved in collaborative learning groups, learners learn a set of prototypes based on the integration of mathematics, science, engineering and technology throughout the study period. A group design a final project at the end of the semester or academic year called the innovative projects (STEM-CAPSTONE).

Stein, et al., (2011) presented five teaching practices that could lead to building a survey-based learning environment:

1) Predictability: It is the teacher's expectation of what the learners will do and the strategies that will be used to solve the problems.

2) Guidance: The teacher provides guidance to learners while trying to solve problems.

3) Selection: Learners select the most effective strategies they used to discuss in the classroom.

4) Sequence: It is the logical sequence of presentations of learners in order to expand the circle of learning.

5) Correlation: It is the sequence of strategies and ideas in a way that helps learners understand the mathematics they learn.

\section{Appropriate modern teaching strategies for STEM}

1. The most important modern strategies of teaching is that the learner plays the main role in the educational process, and the role of the teacher is limited to guidance, not memorization. These methods and strategies came as a result of the development of educational and social philosophical thought, and in response to the emergence of theories of educational psychology (Ryan, 2007, p. 139). 
2 - Schoahin (2016) argues that the most important teaching methods that can be applied in light of the STEM is as follows:• Multi-level lessons, scaffolding, project-based learning, learning contracts, flexible grouping, learning stations, brainstorming, demonstrations, and outdoor specialist.

\section{Criteria of Applying STEM}

The STEM standards for effective manual instruction are based on the definition of the combination of behaviors integrated with the STEM content which are expected from brilliant students. These behaviors include participation in inquiry, logical thinking, cooperation and research. STEM's goal is to prepare students for post-secondary school stage and and the 21st century labor market. STEM has been divided by experts to seven standards in terms of practice (or skills) required to teach students science, technology, engineering and mathematics. It is expected to be achieved by the outstanding students in this program as follows (Tufaida Ghanem, 2012, p. 17; Saleh, 2016, p. 201):

1. Learn and apply the content of science, technology, engineering and mathematics

2. Integrate the content of science, technology, engineering and mathematics

3- Interpret and link information from science, technology, engineering, and mathematics

4. Integrate the investigation

5. Engage in logical thinking

6- Cooperate and work as a team

7. Use and apply technology in creative and professional ways

Global models of STEM

American Model for STEM

The public and private sectors collaborate through a variety of bodies in the implementation of science, technology and innovation strategies in the United States of America. These strategies are developed by the federal government, while their programs are defined by the National Science Foundation (NSF). These programs are evaluated by the National Center for Science, Engineering and Statistics. Science, technology and innovation strategies in the United States focus on Science and Engineering advancement, Research Development, Education employment improvement for the sake of economic growth, Living Standards improvement and achievement of progress in safety and health (National Academy of Science, 2014).

The US National Science and Technology Committee has focused on education and research in the United States in the light of the STEM through five priorities:

To Improve STEM education.

To increase youth involvement and public participation in STEM education.

To enhance the STEM experience at the undergraduate level.

To strengthen STEM education at all levels, and to

design higher education programs in future fields of work.

European Model

Since the 1950s, Europe has begun to develop research and development policies that initially focused on thermal and nuclear energy, the environment and biotechnology. It has then been developed in the 1980s in the setting up strategic programs in information technology research and development of existing industries such as: biotechnology, wireless communications, and manufacturing technology. In the beginning of the current century, Europe's interest in the development of national labor market and science and technology research became increasingly important. The seven general frameworks developed major programs to achieve excellence in science and technology. In 2008, the strategy of science, technology and innovation was developed, which combined higher education, research and commercial market into a single plan. In 2014, European countries agreed on the Horizon 2020 strategy that aimed at developing and creating new jobs in Europe through the implementation of a series of research and renewal programs (European Commission, 2014).

\section{Japanese Model}

In the light of contemporary challenges, Japan seeks to maintain the level of global competition and leadership in science and technology as a result of economic progress in other competitive countries such as China and India. In 2009, the Japanese Cabinet approved a new strategy for economic growth based on a strategy "Science and technology-oriented nation ", believing that science and technology are the basis for economic growth through two 
sub-strategies: the strategy of using green innovations in the environment and energy, and the strategy of renewing life in the field of Public Health (MEXT, 2015).The new strategy is based on the following axes:1) shift from science and technology ( $\&$ \& ) policies to science, technology and innovation (ST \& I) policies; 2) Integrate the development of natural sciences and humanities together.3) Develop and secure human resources and organizations to support targeted policies.4) Develop science and technology policies in cooperation and integration in society and for society (Council for Science and Technology Policy, 2010)

\section{Singapore Model}

Singapore's policy has strengthened mathematics, science and technical skills since 1998 with the formation of the Ministry of Science and Technology. It has been developed in the 1990s with increased attention to human development in high technology and the knowledge economy through post-secondary education and higher education, recognizing that the existence of human capital In science and technology is essential for national development, and the government has made a quantum leap in the education system by focusing on innovation, creativity, and research (Office of the Chief Scientist, 2013).

In 2014, the Ministry of Education of Singapore established the STEM unit, which aims to produce STEM education programs. These programs are developed and implemented by secondary students aged 10-13 years to apply what is learned in solving the problems of the real world, and to create an area for future work in a way that is integrated with high school curricula. The program includes (23) secondary schools, and the program aims to increase to (80) schools in 2017. The programs are designed by specialized experts from the Council of Learned Academies, 2013).

\section{Math teachers preparation program}

The university curriculum includes all the components of the curriculum that includes the university experiences offered to students through the courses specified in the study plan, the teaching methods, the accompanying educational activities, the educational techniques employed, the work and the field training, the methods and the ways of evaluation. These experiences differ from one department to another. depending whether the department be human or scientific. Therefore, Rabab Shatat (2010, p. 78) stated that the Math teachers preparation program consists of three main components: cultural preparation, specialized academic preparation, and professional preparation. This concept is also supported by (Mahmoud, 2005, p. 80) who argues that teachers' preparation begins from joining college of education. Then, he is subject to academic, educational, psychological and cultural preparation during the years of college until graduation. The importance of teacher's lies in the roles of the functional teacher in contributing positive changes in society and development plans in the country. A glance at previous literature and studies such as Dandesh, 2003, p. 100; Al-Ahmad, 2005, p. 19; 2016, pp. 200-201).

This importance is apparent in the following points:

- Good preparation of the teacher is deemed an imperative strategy to address the crisis of low quality education and training for young people in the current era. The adequacy of educational buildings, school equipment, and the efficiency of curricula and teaching methods remain limited if the teacher is not prepared in quality systems.

- The preparation of the teacher helps to strengthen the abilities and cadets of his students, and the dynamic upgrading of their skills and creative quality.

- The higher the levels of preparation and refinement of skills and the better quality of the courses offered, the greater the confidence in the graduates and greater the predicting of their success in the performance of their roles and meet the requirements of the teaching profession.

- There is an increasing need to emphasize the quality of the teacher's preparation, as it is characterized by its professional burdens and the contemporary changes that await it in the continuous development, and the expected tasks in the near future, be educational or technological.

- The good preparation of the teacher leaves a long-term impact on his or her professional career, with his students and parents, with scientific developments and dynamic society aspirations. It also helps to correct the misconceptions and negative attitudes of the future teacher towards the teaching profession and the demands of the educational process

The researcher believes that if the mathematics teacher is competent in the subject he teaches, he is required to teach it with new awareness, new roles and modern strategies to succeed in giving learners the basic skills that constitute the first pillar for acquiring knowledge, information and skills in many subjects. This would not be achieved unless to give a special attention to teachers' preparation as per a carefully plan which is based on solid scientific foundations, which is imposed by the specificity of mathematics and its current status. On the basis of the 
aforementioned points, there seems to be five basic dimensions for good preparation of the Math teacher, which must be taken care of within the courses and programs of teacher training for the future and these dimensions are:

1) Educational dimension: It is specialized to provide teachers with the knowledge and skills that qualify them to teach Math effectively at school and the achieving the roles assigned to them, and the appropriate level of quality in educational performance.

2) academic dimension: which relates to the mastery of the scientific material entrusted to the teacher to explain to his students and to analyze the contents and classification of parts and continue to pinpoint the achievements of scientists

3) The social dimension: It is related to the rules and basics of building a society-based information technology that built on strong ties and relations between its members, building confidence, interaction, participation and exchange of experiences.

4) The technological dimension: It relates to specialized educational software in the management and implementation of learning aspects in mathematics curricula in electronic form, which helps to simplify the complex concepts and representation of the abstract.

5) Administrative dimension: It is concerned with the establishment of steps and stages of general and organized activity and the completion of tasks and work, distributed to learners, organize time, coordination between research teams, and provide follow-up and supervision.

\section{Rationales of developing current Math teachers' preparation program}

The development of the teacher education program is intended to facilitate the institutional work within the faculties of education in order to reach their educational and training programs and plans in the best possible way, starting with activating the mechanisms and procedures to achieve the philosophy of preparing the teacher for the future through developing the sub-goals of each course.Besides that, developing policies of admission for students who meet the requirements of teachers' preparation programs, modernization of existing frameworks for the development of their skills: specialized, educational, cultural, professional, and evaluating the performance of these students in an authentic and comprehensive way (Abdul Hamid, 2015, p. 115).Having a look at literature of the development of teacher education programs and mechanisms in general, and the preparation of the mathematics teacher in particular as a study by NCATE, 2003; Harrachah, 2010, p. 291; Al-Astal, 2015, p. 2; , we conclude a set of justifications, which are:

The relentless pursuit of all international educational systems to make a qualitative leap in the educational process based on the effort of a well- trained and qualified teachers.

The teacher is no longer familiar with the fundamentals of his scientific material and what has been discovered only from the knowledge base. It is sufficient for his professional background and his possession to have an in-depth knowledge base and to acquire the skills of integration and comprehensiveness.

Take preventive measures towards educational, academic and professional errors before they occur, raise the level of community confidence in the competence of the graduate teacher, and utilize his abilities in the employment of modern technology in education.

The importance of effective follow-up and finding the corrective and necessary measures related to the adoption of quality standards in the preparation of the teacher, and the implementation of training programs and the continuing training and good qualification of the student cadres teacher.

The exacerbation of educational problems in the field and within the classroom, which requires pre-teaching training on how to analyze and explore sound scientific methods and propose the best solutions for these problems.

The need for openness to contemporary educational systems that adopt policies of quality assurance and sustainable development, and effective communication with them on what is appropriate to the nature of the current local educational systems.

Lack of a supervisory body qualified to develop education programs.

The need to develop the quality skills of the teacher under preparation, including the ability to choose from alternative information, and to cope with the issues of scientific and specialized modern, and understanding the complex interrelationships between the inputs of the educational process and the roles of organizational quality with them, and the processing of available information and attractive to recall the mind Learners, taking into account the importance of critical method, self-control, team management ... etc. 


\section{Objectives of Math teachers' preparation program}

The objectives of the program of preparing Math teacher in the faculties of education stems from the education policy in the government, which aims to be the goal of the colleges of education to prepare teachers and train them to be able to translate its policy and objectives through the teaching job. Based on this goal, the following objectives have been generated:

1) To prepare of qualified teacher scientifically, culturally and professionally to carry out teaching at all stages of education, and in all scientific and educational disciplines according to a time plan.

2) To adopt the best and latest methods in the preparation of the specialized teacher, and benefiting from the planning of curricula and modern techniques in the field of education, and to use them in the teaching process.

3) To link between the teacher preparation curriculum and philosophy of general education curricula and objectives in general, and the educational stage in which the teacher under preparation will work in particular to enable teachers to understand the message of that stage and help them to better performance in teaching, planning and development.

4- To link the scientific and educational studies in the preparation of the teacher with the Arab society, its values and traditions, and the development plans in the country, in order to meet the country's manpower needs in the fields of education,

5) Ensure that all new teachers acquire the knowledge and skills that help them create a positive climate that supports their training in student learning and prepare Math teacher to be capable of using teaching technology to accelerate student learning.

6) Enable the teacher under preparation from the educational side with its various educational and psychological materials in order to carry out its future roles with great effectiveness, and to the fullest.

From these points, we can highlight the role of the teacher as a component of the educational process in order to be in line with the requirements of modern age that we live in as it has been mentioned by Al-heila (2002, p. 33) and Rashid (2002, p. 78) number of basic roles related to teachers, and it could be determined as :

Educational roles:

To give the learner the abilities of thinking to prepare for the conditions and situations of interaction and achievement, as well as through the type of mental processes and promotion.

To provide the learner knowledge and facts through his engagement on active thinking and learning perceptions, laws and theories.

Provide learners with different skills through explanation, training, practice and use of teaching techniques.

Motivation, is to induce the teacher to the learner's interests, needs and motivation to learn.

Guidance is to advise learners in many roles that concern them, whether educational, personal or social roles.

\section{Educational roles:}

Taking into account the individual differences among the learners, through the variety of teaching methods and methods of assessment according to the abilities of the learner.

Developing values, attitudes, trends and interests through the teacher to advise and guide learners and use the method of encouragement and keep them away from everything that is negative and allow them to carry out positive activities.

Link the school to the community by employing what learners learn from the information, skills and experiences in their social life.

To enrich the curriculum through identifying weaknesses and shortcomings in the elements of the curriculum and filling its gaps through the application of enrichment elements.

\section{Social roles:}

Educating learners about the importance of acquiring habits, positive attitudes and developing the link with the community and emphasizing the interest in the national language.

Consolidate dealing with other social institutions that have a role in helping the school to achieve its objectives such as public libraries, clubs of various kinds, sports, cultural and social, museums and exhibitions, through organizing sites visits to these institutions. 
Forming relationships with the school community; colleagues, learners, parents and educational supervisors in collaboration with the school administration by participating in organizing school activities, interviewing parents and dialogue with them for the benefit of their children.

\section{Administrative roles:}

The role of the teacher in the management of the classroom, and this requires the ability to master organizing the classroom and maintaining the system through the provision of a social emotional atmosphere that would encourage learning and provide educational experiences.

Organize, observe, monitor and evaluate students' work.

Create conditions for good work, its potential, its location, and agree with students to develop a collective action plan, and participate in solving problems that may be encountered in the constructive and final evaluation.

\section{Human Roles:}

Enhancing the value of cooperation. Cooperation is a type of human behavior which is one of the human values.

To achieve mercy and tolerance through the development of the values of tolerance among the educated, compassion, kindness and tolerance open the heartless.

Students are not only influenced by the behavior and behavior of the teacher, but also because they are their teacher and mentor first and foremost. Hence the teacher needed to strengthen his position among them and his competence as a teacher throughout the school year, through his success in their education, and his success in management and organization (Adas, 2000, p. 41).

\section{Challenges that face Math teacher's preparation}

The challenges facing the teacher preparation system are inputs, processes and outputs of the preparation programs. The following is a presentation of these challenges (Al-Hashimi and Marwa El-Baz, 2010, p. 798):1)

Inputs: The method of selecting the future teacher is not based on the scientific basis of selection, and therefore it threatens the quality of the inputs, as well as the lack of correlation in the theoretical preparation of the teacher of mathematics between the specialized courses on the one hand and between the educational and cultural courses on the other hand In the courses of the educational technology, which is taught theoretically in most cases without training the students to use in the teaching and learning situations, and the low number of periods in which the students practice the actual teaching during intrenship which negatively affects the students access to teaching skills and coping with daily activities, and hence on the quality of their preparation in the practical side.

2) Processes: The traditional methods of teaching used by faculty members in the colleges of education, which perpetuates the negative aspects in educational situations. Furthermore, the processes of updating programs and preparation and development occurs in part and not comprehensive, which makes these programs incompatible with the newest trend of the preparation programs.

3) Outputs: The graduate Math teacher may find himself in competition with other graduates from different non-educational faculties, making the mathematics teacher's preparation programs ineffective in preparing the teacher who is able to compete with other graduates.

\section{Previous Studies}

Salaos and Maiman (2010) aimed to identify the reality of the teacher preparation program at the Faculty of Education at Taibah University and then determine the most important criteria proposed for the quality of teacher preparation programs as expressed by faculty members at the Faculty of Education. To achieve this, the study used the analytical descriptive method, and the questionnaire was utilized as a data collection tool, administered to a sample of (144) faculty members. The main findings of the study were that the overall quality of the teacher preparation is a set of criteria and characteristics that must be met in all elements of the institution for all related to the inputs, processes or outputs.

Seeveen and Mohammed (2010) aimed to explore how interaction between science, mathematics and technology would develop the awareness and technical culture of teachers through their teaching science, mathematics and technology. The study adopted the experimental method. To achieve the objectives of the study, the researcher constructed a test in technical culture, as well as a measure of technical awareness as two tools in his research. The sample of the study consisted of (30) teachers in Egypt from the teachers of the intermediate schools in Qena governorate. The results of the study showed the importance of the integration requirements between science, mathematics and technology for teachers, society, curricula designers as well as educational researchers by studying the integration of other subjects. The study pointed to the importance of these requirements for society in achieving technical development, and that the application 
of MST integration faces many difficulties, including the lack of training programs for teachers to use the requirements of integration between science, mathematics and technology.

Niess and Gillow (2013) examined how to improve the performance of science teachers to implement the standards of integration of STEM in teaching. The study has adopted a descriptive analytical approach. To achieve the objectives of the study, the researchers used the questionnaire as a data collection tool. They designed a questionnaire to identify the requirements for developing the performance of eighth grade teachers in science, mathematics and computer science in the light of STEM integration. The study sample consisted of (9) teachers of science, (8) teachers of mathematics and (3) of computers. The results of the study showed that teaching requirements according to STEM integration are directly related to the use of teaching strategies that meet teaching requirements according to STEM integration in science teaching. The study also revealed the need to train teachers before and after service on the use of teaching tools suitable such as mental maps and interactive activities that ensure the existence of the learner in an environment to help build an integrated knowledge related to the curriculum of science and mathematics and computer.

Nelson's (2015) study aimed to enable teachers of the middle school to apply the challenges of integrating STEM to science, technology, engineering and mathematics. To this end, the study followed the descriptive analytical approach, where the researchers used a model to case study. They have also used a questionnaire to collect data and conducted recorded personal interviews. The study sample consisted of (34) sixth, seventh and eighth grade teachers working in two middle schools in the western United States of America, in addition to (45) educated in these schools. The results of the study showed that the STEM Teacher Education Exploration Project provides an example of how to support the application of STEM's educational integration in conventional middle schools, which provided learners with 21st century skills of collaboration, creativity, communication and accountability for team members and others, and initial knowledge of technology and information. The open ends of the STEM integration challenges provided an opportunity for all learners to participate and make valuable contributions. The results also confirm that the integration of learners in problem solving using science, mathematics, engineering and technology involves addition and transformation at the school, district and state level.

Comments on the previous studies

Similarities and differences between the current study and previous studies

Objectives, the current study differed from all previous studies. The present study aims to develop the programs of preparing mathematics teachers in the light of the STEM orientation, which is not targeted by the previous studies. The reviewed studies aimed place effective programs for teachers' preparation. Additionally, they aim to identify the views of students and faculty in the existing teacher preparation programs. Some of the studies of the first axis have also examined the availability of the elements of academic accreditation regarding the quality of teacher's preparation. The most recent studies were the study of Mona Al-Salous and Badriya Al-Maiman (2010), which aimed to identify the reality of teacher education program in the Faculty of Education at Taibah University and to identify the most important criteria proposed for the quality of teacher preparation programs from the perspectives of faculty members towards the STEM.

In terms of the approach, the present study goes in line with most previous studies in adopting the analytical descriptive approach except the study of Seifen and Muhammad (2010) which followed the experimental method.

In terms of the study tool, the current study consisted with most previous studies to use the questionnaire as a data collection tool. However, Sheehy \& Ethyi (2001) and (Nelson, 2015) study used both interviews as well as questionnaire. It also differed from the study of Sivan and Muhammad (2010) which used a test in technical culture, as well as a measure of technical awareness of two data collection tools.

In term of the study sample, the present study is also consistent with (Mina Al-Salous \& Badriya Al-Maiman, 2010; Neyness \& Gillow, 2013; Nelson, 2015) in terms of selecting teachers and university faculty members to form the sample of the study.

\section{How does the current study benefit from the previous studies?}

Take advantage of the results of previous studies to emphasize the importance of STEM's approach to developing teacher education programs and starting where others have ended. Link the results of the current study with the findings of previous studies.

Define the requirements for developing teacher preparation programs in the light of the STEM orientation.

Design of study tools, and develop a proposed vision for the development of teacher education programs in the light of the STEM orientation. 
Take advantage of the literature on the professional development of teachers and the development of teacher preparation programs, requirements and standards of STEM orientation, and the scientific methodology of these studies in enriching the theoretical framework.

Identify the appropriate research methodology for the current study. Identify the appropriate statistical methods for the study.

The novel aspect of the current study

What distinguishes the current study from the previous ones are;

The current study sought to develop a proposed scenario for the development of Math teacher's preparation programs in the light of the STEM orientation. Also, the present study provides a list of STEM requirements for the development of Math teacher's preparation programs.

\section{Methodology}

The analytical descriptive descriptive approach was adopted to analyze the current situation and to monitor the reality of the Math teachers' preparation programs and their specifications in the light of the STEM orientation. The study population was composed of all faculty members in the Math teachers' preparation program in Saudi universities during the academic year (2018-2019). The sample of the study consisted of (47) faculty members who were selected randomly by circulating an e- questionnaire to the study population.

\section{Instruments}

The study tools were:

1) A list of requirements for STEM orientation that should be included in mathematics teacher preparation programs.

2) A questionnaire to determine the extent to which the current programs for the preparation of mathematics teachers are consistent with the requirements of STEM orientation.

3). Proposal for developing Math teacher's preparation programs in light of the STEM orientation.

\section{Results and Discussion}

Q1. What are the STEM orientation requirements that should be included in the professional program for the preparation of math teachers?

To answer this question, the researcher developed a list of STEM requirements that should be included in the professional program for the preparation of mathematics teachers in the light of literature and some previous studies as well as a number of international programs and projects, as depicted in Table 1. 
Table 1. STEM requirements that should be included in Math teachers' preparation programs

\begin{tabular}{|c|c|}
\hline Major Requirements & Sub-indicators \\
\hline $\begin{array}{l}\text { availability of professional competency } \\
\text { for Math teachers under preparation }\end{array}$ & $\begin{array}{l}\text { 1) Teaching mathematics curriculum with high efficiency. } \\
\text { 2) Combine local culture and global learning standards together. } \\
\text { 3) work to improve the critical and analytical side of students. } \\
\text { 4) Owning high efficiency in how to deliver knowledge for students to be developed } \\
\text { later by them. } \\
\text { 5) Finding successful solutions to the difficulties facing them. } \\
\text { 6) Possessing knowledge references that benefit him and develop his potential in the } \\
\text { teaching of mathematics. } \\
\text { 7) Ability to solve the problems faced by students. } \\
\text { 8) Awareness of basic facts such as concepts, principles, rules and theories in the } \\
\text { fields of mathematics. } \\
\text { 9) Ability to connect ideas across sub-mathematics disciplines. } \\
\text { 10) recognition of practices and methods that promote knowledge about the natural } \\
\text { world. } \\
\text { 11) Using mathematics to solve problems in the real world using geometry. } \\
\text { 12) Knowledge of the strategies and methods of teaching mathematics in the light of } \\
\text { STEM orientation. } \\
\text { 13) Ability to guide students' abilities through extracurricular activities and } \\
\text { programs. } \\
\text { 14) Familiarity with the elements needed to develop and implement integrated } \\
\text { STEM approaches and programs. } \\
\text { 15) Teaching Engineering Concepts and Engineering Design. } \\
\text { 16) Application of e-learning and use of software. } \\
\text { 17) Design practical activities based on action and thinking. } \\
\text { 18) Apply post-school learning strategies. } \\
\text { 19) Apply search-focused activities. } \\
\text { 20) Ability to use modern techniques in education. } \\
\text { 21) Use basic software in drawing and engineering design. } \\
\text { 22) Ability to identify and understand the role that mathematics plays in the world. } \\
\text { 23)The use of mathematics in ways that meet the needs of the individual as a citizen } \\
\text { contributes to the building of society. } \\
\text { 24)Express mathematical ideas using appropriate mathematical terms. } \\
\text { 25) Apply the concepts and skills of mathematics in everyday life. }\end{array}$ \\
\hline $\begin{array}{r}\text { Commitment of teachers to improve } \\
\text { students' performance }\end{array}$ & $\begin{array}{l}\text { 1) the ability to modify the cognitive structure of learners and teaching methods. } \\
\text { 2) Use teaching techniques to keep students in an organized learning environment. } \\
\text { 3) Develop and develop the necessary rules to stimulate social interaction between } \\
\text { learners and teachers. } \\
\text { 4) Motivate learners and encourage them to learn as required. } \\
\text { 5) Communicate with parents on assessing the progress of the learner level. } \\
\text { 6) Facilitate the process of learning and absorbing learners appropriately. } \\
\text { 7) The belief that all learners are able to learn. } \\
\text { 8) Treat all learners equally and fairly. } \\
\text { 9) Identify individual differences among learners and transform them into energies } \\
\text { that serve learning. } \\
\text { 10) Attention to develop the concept of self learners. } \\
\text { 11) Raise the level of knowledge of learners and their desire to learn. Application of } \\
\text { theories of knowledge, learning and personal intelligence }\end{array}$ \\
\hline $\begin{array}{cccc}\text { Teachers } & \text { utlize } \begin{array}{c}\text { foundation of } \\
\text { systematic thinking }\end{array}\end{array}$ & $\begin{array}{l}\text { 1) it is considered a model and an example of the learner. } \\
\text { 2) It enhances their teaching abilities by drawing on the experiences of others. } \\
\text { 3) It has intellectual reasoning to adopt several views. } \\
\text { 4) It has the ability to male teacher under preparation criticize himself and discover his } \\
\text { mistakes. } \\
\text { 5) It adopts the foundations and methods of methodological and experimental problem } \\
\text { solving. } \\
\text { 6) It has the ability to direct his teaching knowledge to develop students' abilities. } \\
\text { 7) It has the ability to direct his teaching knowledge to improve his level in teaching } \\
\text { mathematics. } \\
\text { 8) It understands the requirements of students to determine the best means to improve their } \\
\text { level. } \\
\text { 9). The ability to apply new ideas and theories to the educational process in a good way. }\end{array}$ \\
\hline $\begin{array}{c}\text { Teachers' involvement in educational } \\
\text { community }\end{array}$ & $\begin{array}{l}\text { 1)To contribute to improving the efficiency of the school through its cooperation with the } \\
\text { educational community. } \\
\text { 2) Ability to distribute school resources through its role as a teacher. } \\
\text { 3) Assess the progress of the school in achieving the goals set. } \\
\text { 4) Follow the objectives set. } \\
\text { 5) Cooperation with school members and parents. }\end{array}$ \\
\hline
\end{tabular}

Q2: What are the realities of math teachers' preparation programs 
To answer this question, means, standard deviation and the percentage of sample responses on each sub-index were calculated according to the quadratic scale to identify the reality of mathematics teacher preparation programs in the light of the STEM, as shown in Table 2.

Table 2. Reality of math teachers' preparation program in light of STEM

\begin{tabular}{l|l|l|l|l|l}
\hline Ser & Main Requirements & M & SD & $\%$ & Degree \\
\hline & $\begin{array}{l}\text { The interaction of pre-Math } \\
\text { teachers in the educational } \\
\text { community. }\end{array}$ & 2.46 & 0.585 & $\% 82$ & high \\
\hline $\begin{array}{l}\text { The use of pre-Math } \\
\text { teachers to the basics of } \\
\text { systematic thinking. }\end{array}$ & 2.37 & 0.675 & $\% 79$ & high \\
\hline $\begin{array}{l}\text { Students commitment to } \\
\text { mathematics teachers to } \\
\text { improve the performance of } \\
\text { learners. }\end{array}$ & $\begin{array}{l}\text { Proficiency of pre-Math } \\
\text { teachers in light of STEM } \\
\text { orientation }\end{array}$ & 1.49 & 0.399 & $\% 73$ & moderate \\
\hline & Overall mean & 2.13 & 0.565 & $\% 71$ & moderate \\
\hline
\end{tabular}

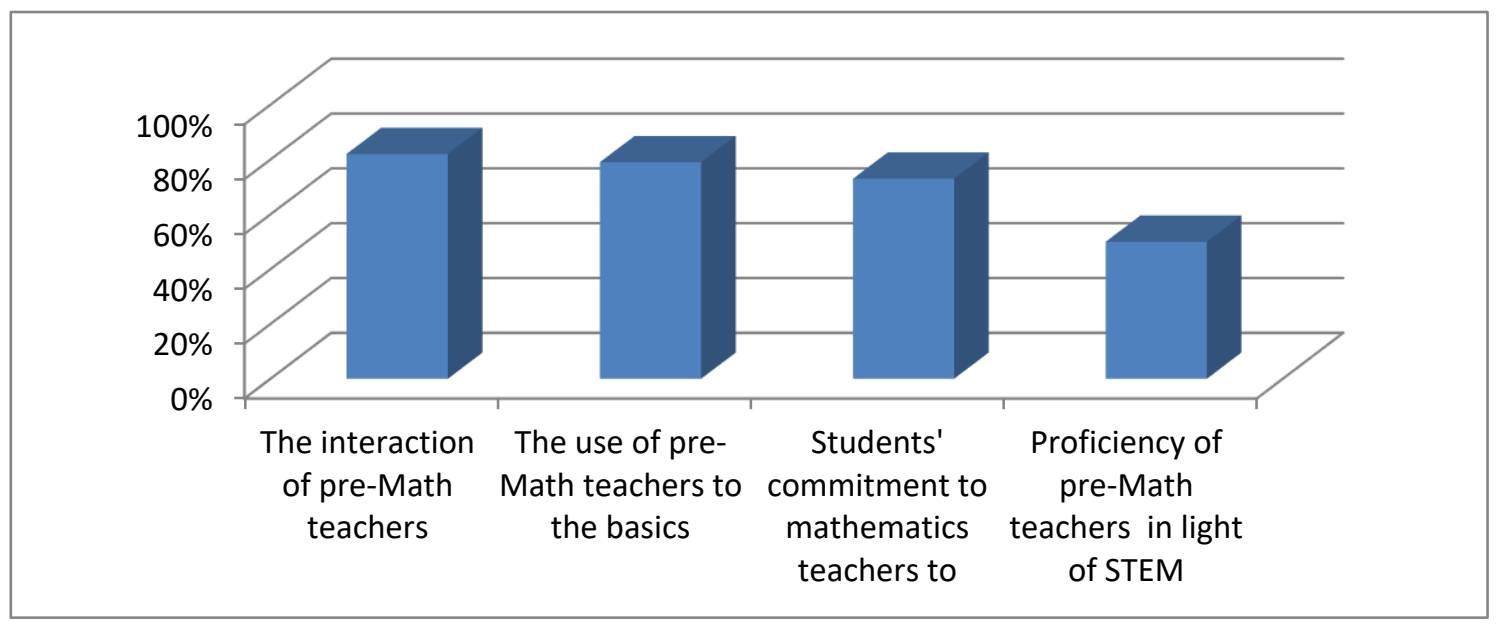

Figure 1. Reality of Math teachers' preparation programs in light of STEM

It is evident from Table (2) and Figure (1) that the reality of the pre-service Math teachers preparation programs obtained a moderate degree $(\mathrm{M}=2.13, \mathrm{SD}=.565,71 \%)$. The requirement of "the interaction of pre-service Math teachers in educational community" reached first degree $(M=2.46,=82 \%)$, followed by the requirement of "the use of pre-service Math teachers the basis of systematic thinking" in second place with $(\mathrm{M}=2.37,79 \%)$, and then the requirement of "commitment pre-service Math teachers to improve the performance of learners "ranked third (M 2.19, $73 \%$ ), and finally the requirement of" professional competence of pre-service Math teachers in the light of the trend of STEM "ranked fourth $(\mathrm{M}=1.49$, and $50 \%)$.

These results are in line with the findings of Mona Al-Salous and Badriya Al-Maiman (2010) that the overall quality of the teacher's preparation is a set of criteria and characteristics that must be met in all components of the institution for all inputs, processes or outputs.

The results of the current study were also consistent with Sivan and Muhammad (2010) who found that there were no training programs for teachers to use the requirements of integration between science, mathematics and technology. It also went in line with Nayss and Gillow, 2013; Nelson, 2015, which recommended that teachers should be trained before and after service to meet the requirements of STEM. Open ends of STEM integration challenges provided all 
students with the opportunity to participate and make valuable contributions. It is advisable to integrate learners in solving problems by using science, mathematics, engineering and technology to include addition and transformation at the school, district and state level.

However, the findings of the present study contradict with those of Patricia Emmerich \& Ney (2002) who found that equipment as per to the latest technologies, the active participation of faculty members in the work and the importance of increasing the period of practical education for students of faculties of education were positive. The different results could be attributed to low availability of STEM requirements in mathematics teacher preparation programs, especially in the professional competence of teacher students, to their lack of familiarity with the elements needed to develop and implement the integrated STEM curriculum and programs, their use of mathematics in a purely way away from being linked to meeting the needs of the individual and the community, and their inability to identify and understand the role played by mathematics in science, and the combination of local culture and global learning standards.

Q3. What is the suggested professional program to prepare Math teachers in light of STEM?

Based on the results achieved, the researcher initiated the proposed development of the professional program for the preparation of mathematics teachers in the light of the STEM approach, taking into account the weakness of the findings of the current study and enhancing the strengths. The researcher developed the study plan for the program by reviewing the previous studies and pedagogical literature related to the STEM and the international experiences in this field and the scientific movement towards this direction through the orientations of the KSA Ministry of Education and the local and international scientific centers which summarized the list of requirements previously prepared. The researchers has determined the following requirements

:1) Program name.

2) Objectives of the proposed program

.3) The number of credit hours for the proposed program

.4) Distribution of credit hours on the requirements of specialization and college. framework).

5) Intended learning outcomes targeted by the program (after being guided by the national qualifications

6) Justifications for the opening of the new program (cultural, social, economic ...).

7) Course specification.

Phase II: External benchmarking and identification of labor market needs:

Step 1: External benchmarking comparison.

Step 2: Identify the training needs of program participants.

Phase III: Information Analysis.

Phase 4: Final Design for Proposed Development of the Program: This phase includes the description of the program and the syllabus according to the models of the National Commission for Academic Assessment and Accreditation (June 2017), as follows

1) Prepare the proposed development specification of the program.

2) Prepare specifications for of all the programs courses.

3) Prepare specification of a field experience course.

4) The distribution of courses at the proposed levels of study taking into account the requirements of the courses and their scientific and logical sequence.

5) Ensure that there are no repetitions in the courses, or gaps in the scientific content.

6) Ensure that the intended learning outcomes of the courses are aligned with the knowledge and skills matrix of the program.

Phase 5: Administrative and regulatory procedures for the approval of the program through the passing through boards of departments, colleges, and postgraduate studies at the university until the program is approved.

Study Recommendations

In light of the results revealed by the study, the researcher recommends the following:

1) Developing a strategic plan to identify the actual training needs of the pre-service math teachers preparation program in general in light of the requirements of the integration of STEM. 
2) Making use of the proposed scenario presented by the current study in the development of the program of preparing mathematics teachers in the light of the STEM.

3) Benefiting those who involved in the professional development of teachers from the results of the current study, and adopt the STEM in the teaching of mathematics curricula in particular, and the scientific materials curricula in general as a trend proved to be effective in several advanced countries in term of education.

4) disseminating the concept of STEM among all employees of the Saudi educational community through the holding of workshops, conferences and scientific meetings in this orientation and requirements.

5) Strengthening the capacity of pre-service mathematics teacher programs to identify and understand the role of mathematics globally, and how to benefit from global experiences that have succeeded in taking the STEM approach.

Study proposals

In light of the results of the study and linking them to previous studies, the researcher suggests the following:

1) Conducting a study on the reality of the programs of preparation of mathematics teachers in the light of the system of leadership supervision and school performance.

2) Evaluation of teacher preparation programs at Imam Muhammad bin Saud Islamic University in light of the requirements of the integration of STEM.

3) Integrating STEM as one of the modern strategies in teacher education programs in Saudi Arabia.

4) Doing an analytical view of the reality of teacher training programs in international experiments.

\section{References}

Abdul Hamid, H. A. (2015). A proposed program in the methods of teaching mathematics in light of quality standards and its impact on the development of achievement and teaching performance of female students teachers popular basic education, unpublished doctoral thesis, Faculty of Education, Ain Shams University.

Adas, M. A. (2000). Effective teacher and effective teaching, and school applications. I 2, Syria: Modern Education House.

Al-Ahmad, K. T. (2005). Forming teachers from preparation to training, University Book Publisher, Dar Al-ain, UAE.

Alastal, I. H. (2015). The needs of the professional development of the teachers of mathematics in the upper elementary stage in the schools of the Gaza Strip in light of the standards of school mathematics. Journal of Faculty of Education, Banah University, 26(101), 1-48.

Alharasha, M. A. (2010). Teacher's preparation in light of organized instructional overall quality standards. Third Scientific Conference of the Faculty of Education, Jerash University. Faculty of Education, Jerash University, Jordan, April, 289-304.

Al-Heila, M. M. (2002). Teaching skills. Amman: Dar Al Masirah for Publishing and Distribution.

Al-Otaibi W. H. (2016). Preparation of science teacher in the light of the overall quality standards, a suggested proposal. 6th International Arab Conference for Quality Assurance of Higher Education, Cairo, 81-92.

Aqeel, H. A. (2016). Preparation of secondary school teacher in the faculties of education in the Kingdom of Saudi Arabia in the light of the overall quality standards: an analytical study. Journal of Al-Azhar University, 1(168), 233-305.

Dandesh, F. M. (2003). Guide to practical education and teacher training. Alexandria: Dar El Wafaa Press.

Elipane, L. (2012). Towards the Embodiment of Competency Standards: Incorporating the Elements of Lesson Study in The Pre-Service Mathematics Teacher Education In The Philippines. The Asia-Pacific Education Researcher, 21(2).

Ghanem, T. S. (2011). High school curriculum in the light of the entrance to science, technology, engineering and mathematics STEM. Paper presented to the Fifteenth Scientific Conference "Scientific Education New Thought". Cairo.

Ghanem, T. S. (2012). Design of outstanding curricula in the light of the STEM entrance (Science-Technology-Engineering-Mathematics Design). National Center for Educational Research and Development. Curriculum Development Research Division.

Harrison, M. (2011). Supporting the T and the E in STEM: 2004-2010. Design and Technology Education: An International Journal, 16(1), 17-25. 
Hashemi, A. (2010). Evaluation of the educational component of the preparation of the Arabic language teacher at the Faculty of Education at Sultan Qaboos University from the perspective of graduates. Journal of Educational Studies, Sultanate of Oman, 4 (1).

Kalogiannakis, M., \& Papadakis, S. (2019). Evaluating pre-service kindergarten teachers' intention to adopt and use tablets into teaching practice for natural sciences. Int. J. Mobile Learning and Organisation, 13(1), 113-127. https://doi.org/10.1504/IJMLO.2019.096479

Kalogiannakis, M., \& Papadakis, S. (2018). A proposal for Teaching ScratchJr Programming Environment in Preservice Kindergarten Teachers. In Finlayson, O., McLoughlin, E., Erduran, S., \& Childs, P. (Eds.), Electronic Proceedings of the ESERA 2017 Conference. Research, Practice and Collaboration in Science Education, Part 15/Strand 15 (co-ed. Bodil Sundberg \& Maria Kallery, Early Years Science Education), (pp. 2095-2105). Dublin, Ireland: Dublin City University. ISBN 978-1-873769-84-3

Keshta, A. (2012). The reality of the quality of the programs of preparing the teacher of technological education in the Palestinian universities and colleges in the Gaza Strip. Journal of the Educational Society of Social Studies, (41), 171-206.

Khajah, B. B. (2016). A suggested proposal to develop professional development programs for science teachers in the light of contemporary global trends. Unpublished PhD thesis, Faculty of Education, Department of Curriculua and Instruction, Taibah University.

Mahmoud, N. M. (2005). Configure math teacher and access to quality. Fifth Scientific Conference, Egyptian Association of Mathematics Education, July 20-21, Guest House, Ain Shams University, 78-83.

Michael, N. D. (2004). Principles and Levels of School Mathematics 2000 "Curriculum and Evaluation". Egyptian Society for Mathematics Education, Annual Scientific Conference School Mathematics: Standards and Levels, pp. 21-36.

Murad, S. S. (2014). A proposal for a training program to develop the teaching skills of high school physics teachers in light of the principles and requirements of the integration of science, technology, engineering and mathematics STEM in Hail, Saudi Arabia. Arab Studies in Education and Psychology (ASEP), 3(56).

National Research Council. (2011). Approaches in science, technology, engineering and mathematics: Successful K-12 STEM education. Washington: National Academy of Sciences.

Nelson, T. H. (2015). Supporting Middle School Teachers' Implementation of STEM Design Challenges. Vancouver. U.S.A: Washington State University.

Niess, M. L., \& Gillow-Wiles, H. (2013). Advancing K-8 teachers' STEM education for teaching interdisciplinary science and mathematics with technologies. Journal of Computers in Mathematics and Science Teaching, 32(2), 219-245.

Papadakis, S. (2018). Evaluating pre-service teachers' acceptance of mobile devices with regards to their age and gender: a case study in Greece. International Journal of Mobile Learning and Organisation, 12(4), 336-352. https://doi.org/10.1504/IJMLO.2018.095130

President's Council for Science and Technology PCAST. (2010). prepare and inspire: K-12 science, technology, engineering, and math (STEM) education for America's future. Washington, DC: PCAST.

Ramadan, S. (2005). Developing teacher preparation systems in the faculties of education in the Sultanate of Oman in light of the comprehensive quality standards Zagazig University. Journal of the Faculty of Education, 15(60).

Rashed, A. (2002). Characteristics of the Egyptian teacher and his roles, supervision and training. Cairo: Dar Alfekr Alarabi

Ryan, M. H. (2007). Design of educational system and application models. Amman: Dar Haneen.

Salous, M., \& Al-Maiman, B. (2010). Towards academic standards for the quality of teacher preparation in the faculties of education at Taibah University from the point of view of faculty members. The 15th Annual Meeting, Saudi Society for Educational and Psychological Sciences, 45.

Sefine, M., \& Mohammed, I. (2010). Strategic effectiveness based on the interaction between mathematics, science and technology to develop the culture and technological awareness of teachers. The 10th Scientific Conference of Fayoum College of Education "Educational Research in the Arab World: Future Perspectives". pp. 294-331. Egypt. 
Shahrani, F. Y. (2013). A proposed training program for the development of teaching performance skills for high school physics teachers in light of the requirements of integration between science, mathematics and technology. Unpublished Master Thesis, Faculty of Education, Department of Curricula and Methods of Teaching Science. King Khalid University.

Shatat, R. M. (2010). Evaluation of the program of preparing mathematics teachers in the Faculty of Education in light of the quality standards (teachers' standards). The Third Annual International Scientific Conference: Quality Standards and Accreditation in Open Education in Egypt and the Arab World, (2), 27-28 March

Shawahin, K. S. (2016). Recent Modes in Education: STEM Program Applied Models of Science, Technology, Engineering and Mathematics: Jordan. Irbid: The World of Modern Books.

Stein, Gary S., Luong, Mai X., Shi, Meng-Jiao, Smith, Kelly P., Vazquez, Priscilla. (2011). Human STEM CELL Technology and Biology. U. S. A: Wiley-Black Well. https://doi.org/10.1002/9780470889909

Thomasian, J. (2011). Building a science, technology, engineering, and math education agenda: An update of state actions, National Governors association. Washington. DC: National Governors Association Centre for Best Practices.

Tsupros, N., Kohler, R., \& Hallinen, J. (2009). STEM education: A project to identify the missing components, Intermediate Unit 1 and Carnegie. Pennsylvania: Mellon.

Vasquez, Jo Anne; Sneider, Cary; Comer, Michael. (2013). STEM Lesson Essentials, USA: Heinemann.

Yousef, H. (2009). Evaluation of teaching performance of teachers of mathematics in secondary education in the light of the method of functional competencies - field study in secondary education institutions of the state of Jijel. Unpublished PhD thesis. University of Mentori. Constantine. Algeria.

Zaitoon, H. H. (2006). Teaching Skills: Vision in the implementation of teaching. Cairo: Alam Alkutob.

\section{Copyrights}

Copyright for this article is retained by the author(s), with first publication rights granted to the journal.

This is an open-access article distributed under the terms and conditions of the Creative Commons Attribution license which permits unrestricted use, distribution, and reproduction in any medium, provided the original work is properly cited. 